\title{
The Relationship between Psychological Capital and Job Adjustment of Staffs in Kermanshah University of Medical Sciences (The Study of Mediator Role of job Self-efficacy)
}

\author{
Sohaila Jalilian (MSc) ${ }^{1}$, Ghaffar Karimianpour (MSc) $)^{2, *}$ \\ ${ }^{I}$ Department of Educational Sciences, Faculty of Educational Sciences and Psychology, Peyam noor University, \\ Kermanshah, Iran \\ ${ }^{2}$ Young Researchers and Elite Club, Kermanshah Branch, Islamic Azad University, Kermanshah, Iran
}

* Corresponding Author: Ghaffar karimianpour, Young Researchers and Elite Club, Kermanshah Branch, Islamic Azad University, Kermanshah, Iran. Email: karimiangh@gmail.com

\begin{tabular}{|c|c|}
\hline & Abstract \\
\hline $\begin{array}{l}\text { Received: } 20 / 01 / 2017 \\
\text { Accepted: } 15 / 11 / 2017\end{array}$ & $\begin{array}{l}\text { Background and Objective: Job adjustment as a psychosocial well-being } \\
\text { and adaptive state of the individual to post-employment occupation has } \\
\text { positive effects, which necessitates identifving the factors that affecting it. }\end{array}$ \\
\hline $\begin{array}{l}\text { How to Cite this Article: } \\
\text { Jalilian S, Karimianpour G. The } \\
\text { Relationship between Psycho- } \\
\text { logical Capital and Job } \\
\text { Adjustment of Staffs in } \\
\text { Kermanshah University of } \\
\text { Medical Sciences (The Study of } \\
\text { Mediator Role of Job Self- } \\
\text { efficacy). Pajouhan Scientific } \\
\text { Journal. 2018; 16(3): 39-47. } \\
\text { DOI: } 10.18869 / \text { psj.16.3.39 }\end{array}$ & $\begin{array}{l}\text { This research aims to study the mediator role of job self-efficacy in the } \\
\text { relationship between psychological capital and job adjustment among staffs } \\
\text { of Kermanshah university of medical sciences. } \\
\text { Materials and Methods: This study is a descriptive correlational study and } \\
\text { applied in structural equations model (SEM).According to the Morgan } \\
\text { table and using convenience sampling method, } 122 \text { employees of } \\
\text { Kermanshah university of medical sciences ( } 92 \text { men and } 30 \text { women) were } \\
\text { selected in 2016. Data were collected using Luthans Psychological Capital } \\
\text { Questionnaire, Rigs and Knight Professional Self-efficacy Questionnaire } \\
\text { and Dawis \& Lofqist Job Adjustment Questionnaire. Data were analyzed } \\
\text { by mean, standard deviation, Pearson correlation, KMO and Bartlett test } \\
\text { with SPSS v. } 22 \text { and LISREL v. } 8.8 \text { softwares. } \\
\text { Results: The results showed that the direct effects of psychological capital } \\
\text { on job self-efficacy and job adjustment is significant and also job self- } \\
\text { efficacy has direct effects on job adjustment. The mediator role of job self- } \\
\text { efficacy in relationship between psychological capital and job adjustment } \\
\text { of employees is also significant. } \\
\text { Conclusion: Psychological capital and job self-efficacy are variables that } \\
\text { effects on job adaptability and should be regarded and strengthen by the } \\
\text { university administrators in the staffs. }\end{array}$ \\
\hline & Keywords: Adjustment; Capital; Job; Psychological; Self-efficacy \\
\hline
\end{tabular}


dot: $10.18869 / \mathrm{psj} .16 .3 .39$

\title{
ارتباط بين سرمايهى روانشناختى و سازكارى شغلى كاركنان علوم يزشكى كرمانشاه:

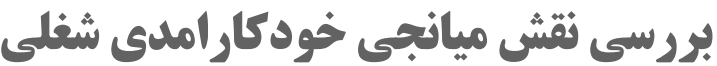

\author{
سهيلا جليليان'، غفار كريميان يور \\ ' كروه علوم تربيتى، دانشكده علوم تربيتى و روانشناسى، دانشخاه يُيام نور، كرمانشاه، ايران

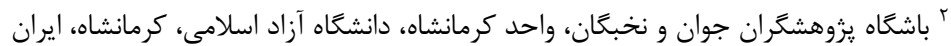

* نويسنده مسئول: غفار كريميان يور، باشَاه يزوهشَران جوان و نخبكان، واحد كرمانشاه، دانشعاه آزاد اسلامى، كرمانشاه، ايران.

ايميل: karimiangh@gmail.com

جكيده

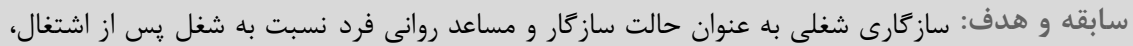

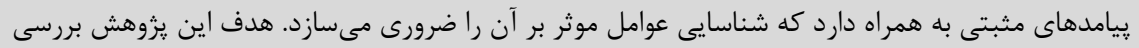

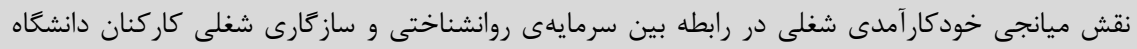

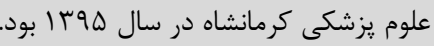

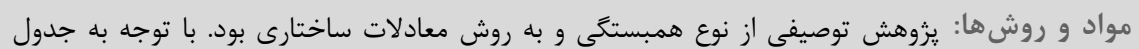

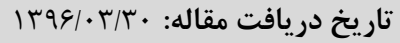

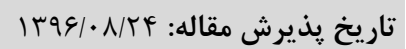
تمامى حقوق نشر براى دانشكاه علوم يزشكى همدان محفوظ است.

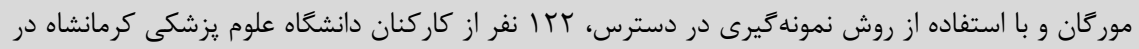

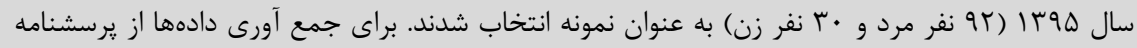

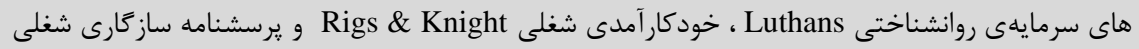
Dawis \& Lofqist

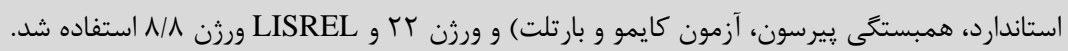

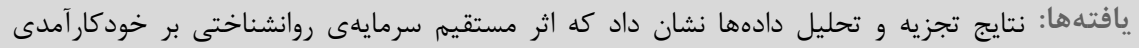

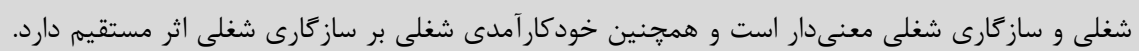

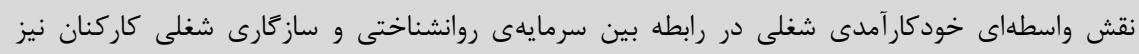
معنادار بود.

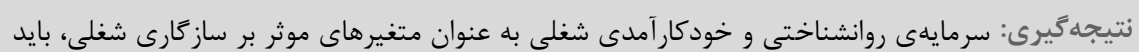

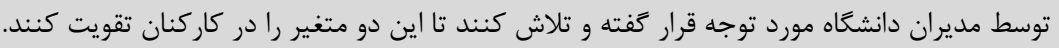
وارَّان كليدى: سازگًارى؛ سرمايه؛ خودكار آمدى؛ روانشناختى؛ شغل

سازگًارى فرآيندى در حال رشد، تحول و يوياست. شامل

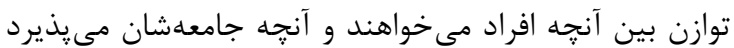

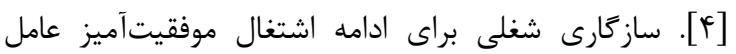

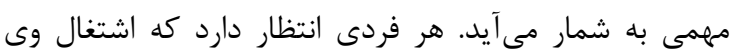
موجب خشنودى و سلامت و اعتبار وى كردد و حداقل نيازهاى مهاى

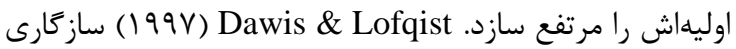
شغلى را شامل تطابق شخصت فرد با عوامل محيطى مرتبط با مر بارد كار مى مانند [ه]. سازگارى شغلى را با كاهش تعارض و افزايش كارائى در كار

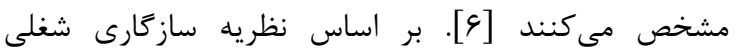

در عصر حاضر كه تغييرات و تحولات محيطى از

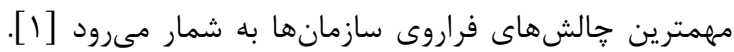

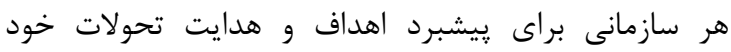
نيازمند نيروى انسانى با سازگارى و عملكرد شغلى مانى مطلوب

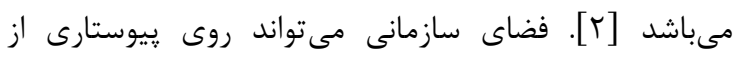

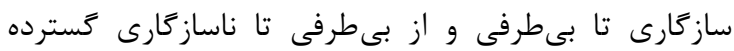

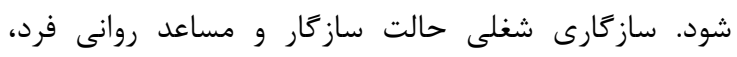

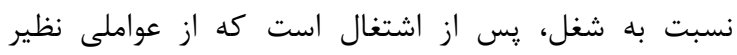

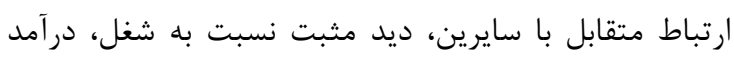

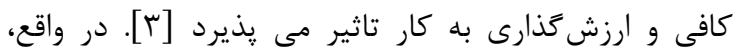


معنا بخشيده، تلاش فرد براى موقعيتهاى فشارزا را تداوم

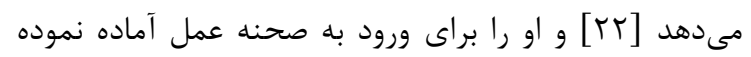

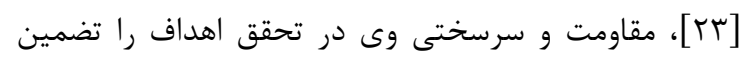

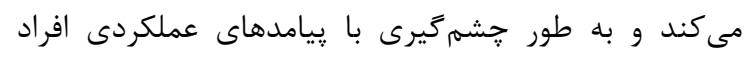

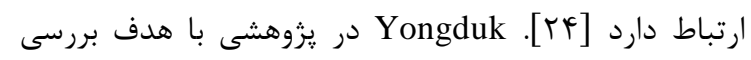

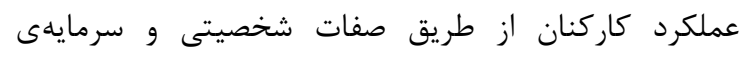
روانشناختى نشان دادند كه عملكرد درك شده در ابعاد قصد

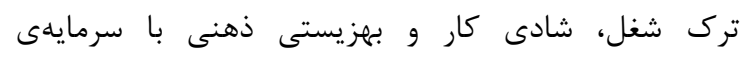

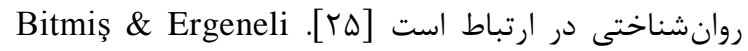

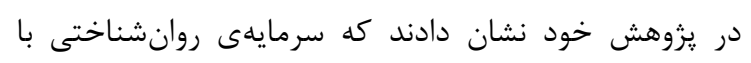

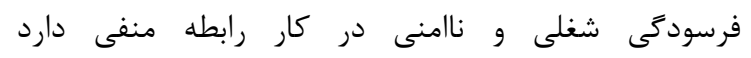

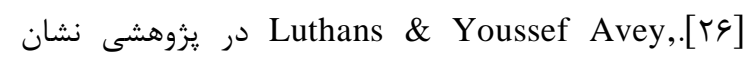
دادند كه سرمايهى روانشناختى با قصد ترى شغل رابطه

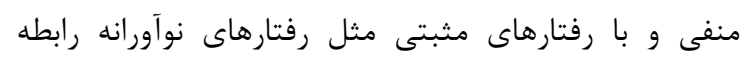

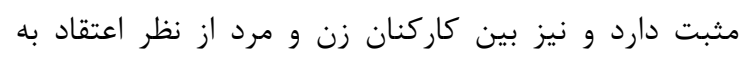

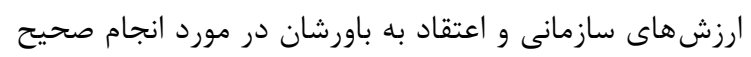

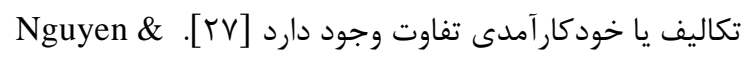

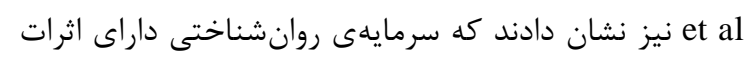

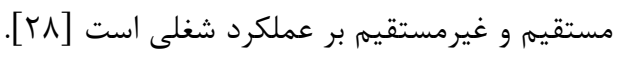
يافتهاى شريفى و شاهطلبى حاكى از آن است كه بين

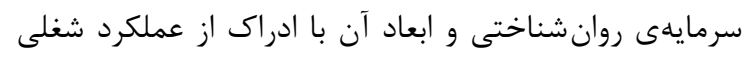

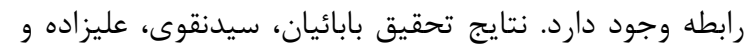

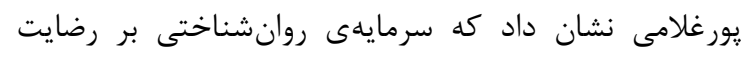

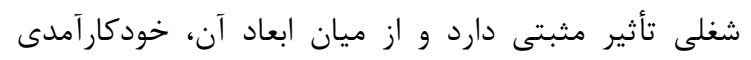

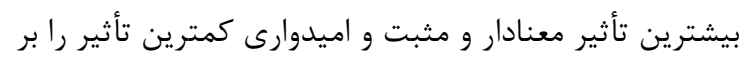

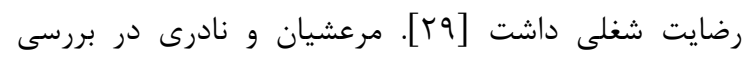

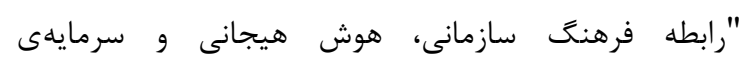

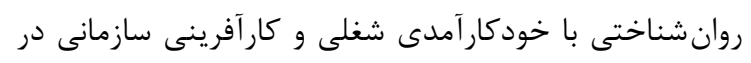

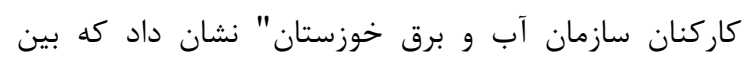

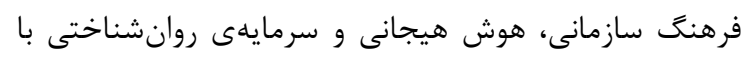
خودكارآمدى شغلى و كارآفرينى سازمانى هانى رابطهى مانى معنادار

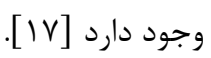

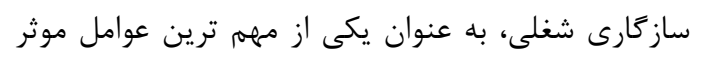

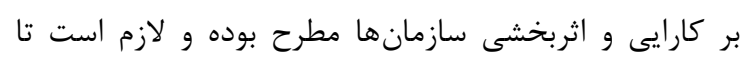

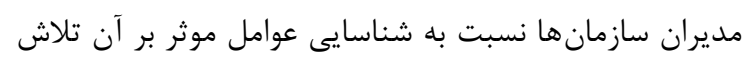

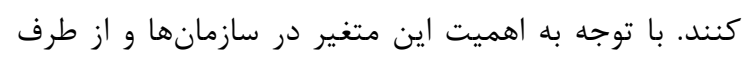

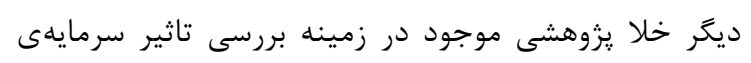

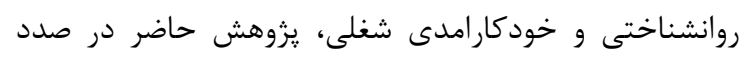

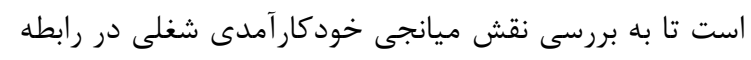

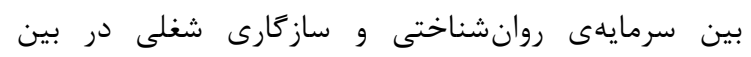
كاركنان دانشعاه علوم يزشكى كرمانشاه بيردازد.

موان و روشها روش انجام اين تحقيق توصيفى از نوع همبستخى
مفهم (1991) Dawis \& Lofqist مفهوم ارتباط بين فرد (شخصيت شغلى) و محيط (محيط شغلى) يك ارتباط هماهنَ و دوسويه است كه شكل مطلوب

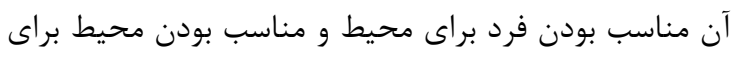

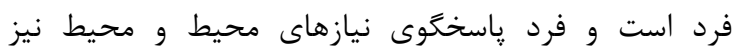

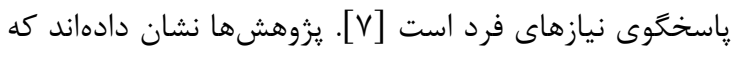

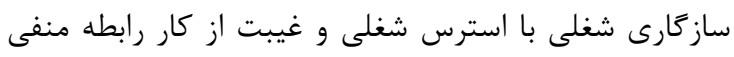

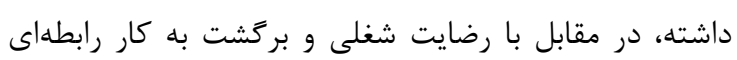

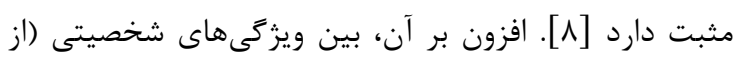

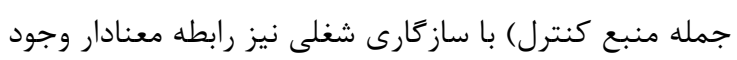

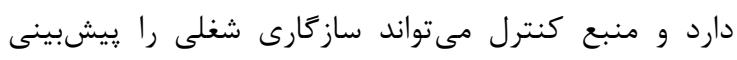

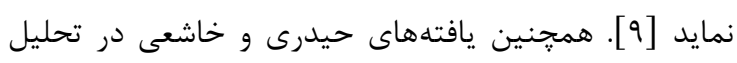

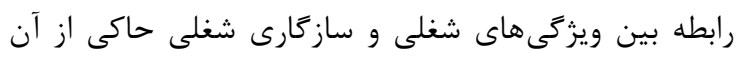

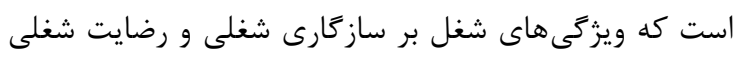
تأثير مستقيم دارد [ [1].

مرور يزوهش هاى كذشته نشان مى مهدد كه يكى از عوامل

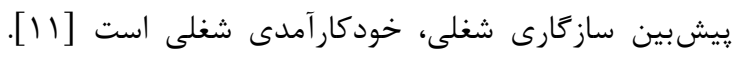

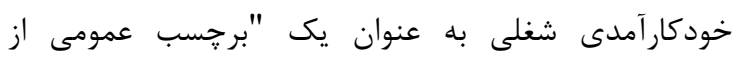

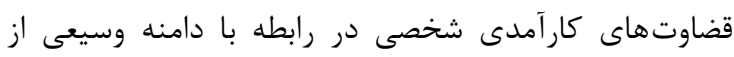

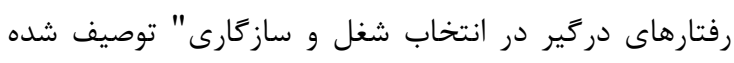

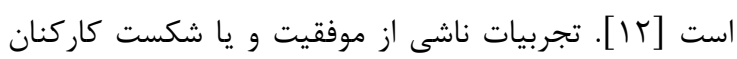

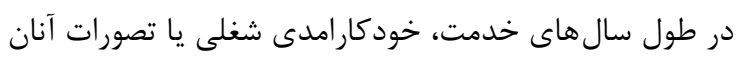

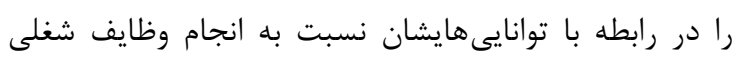

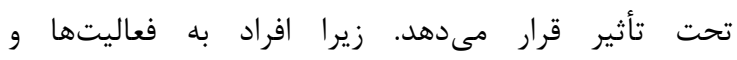
موقعيت هايى كرايش دارند كه احساس كنند توانايى ساز كارى

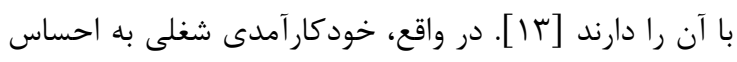

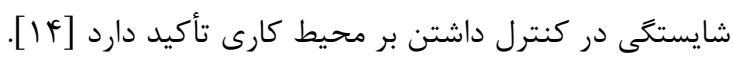

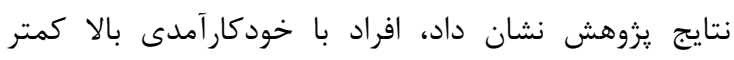
مضطرب و ناميد مىشوند و در برابر موقعيتهاى ندان تنشزا كمتر شاكى هستند و از خوشبينى بيشترى نسبت بـ به آينده

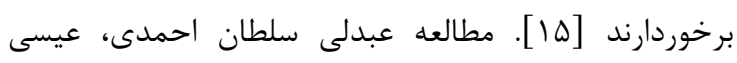

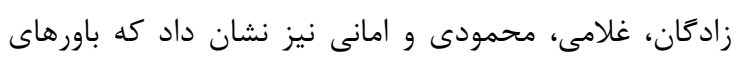

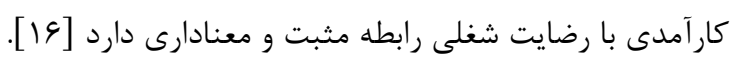
خودكارآمدى شغلى تحت تاثير عوامل مختلفى قرار دارد.

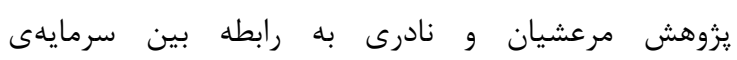

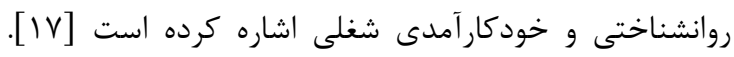

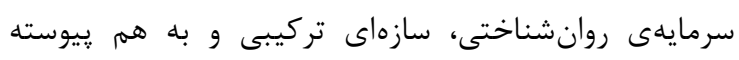

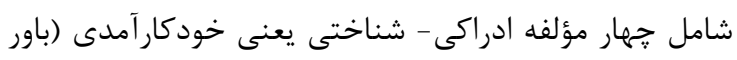

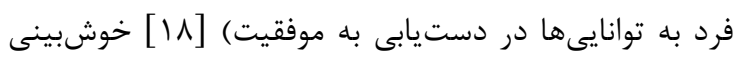

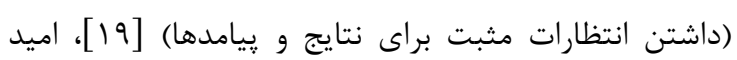

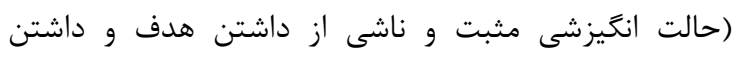

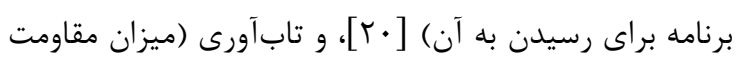

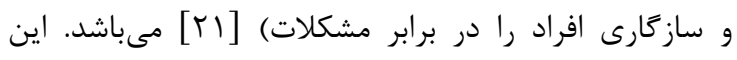

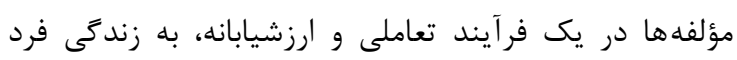




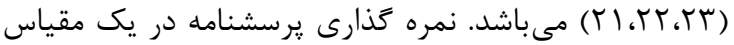

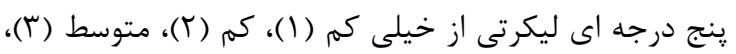
زياد (F) و خيلى زياد (ه) بود. روايى محتوايى زيرسئ رسشنامه

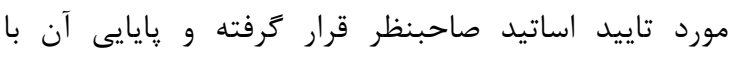
استفاده از روش آلفاى كرونباخ در اين يزوهش صورديد

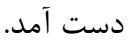

دادهها با استفاده از نرم افزار SPSS نسخه كار

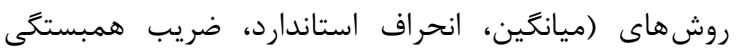

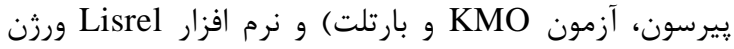

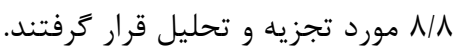

\section{بافته هن}

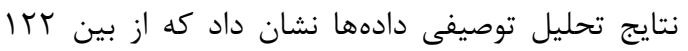

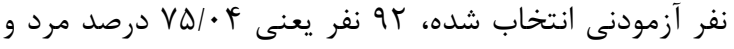

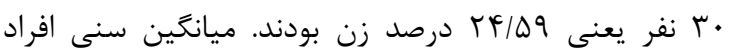

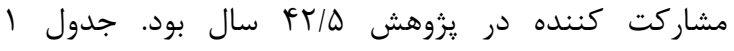

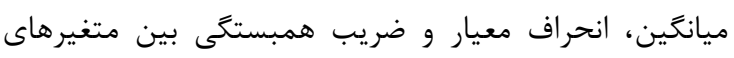
يزوهش را نشان مى دهد.

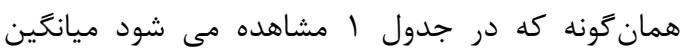

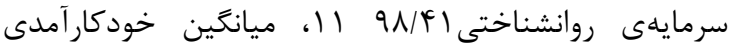

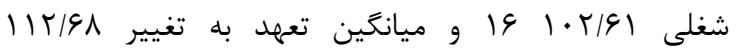
مىباشد. همجنين بين متغير سرمايهى روانشناختى بارئ

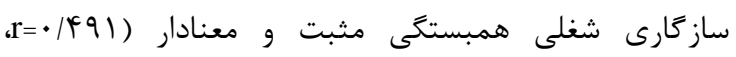

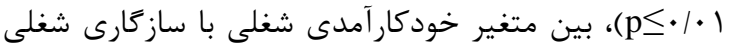

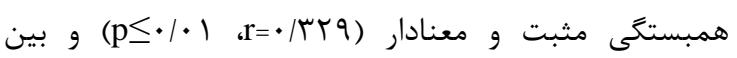

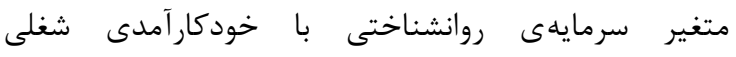

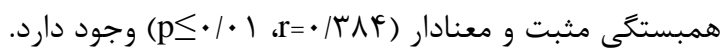

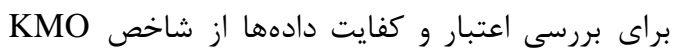

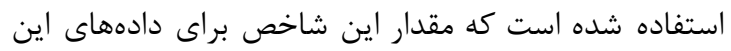

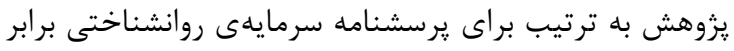

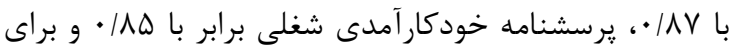

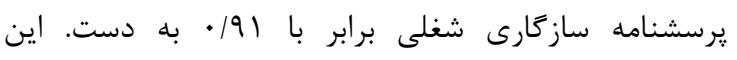

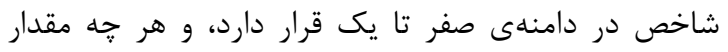

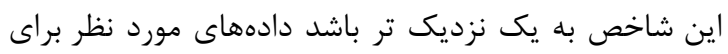

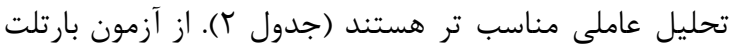

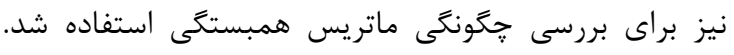

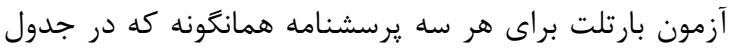

مىباشد. جامعه آمارى اين يزوهش شامل تمامى كاركنان

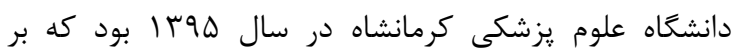
اساس جدول مورگَان تعداد و با استفاده از روش نمونه گَيرى

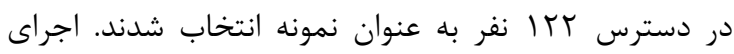

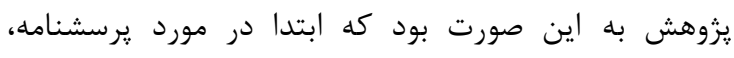

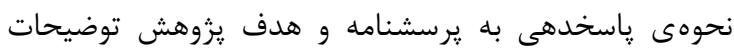

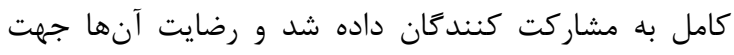

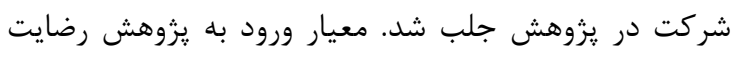

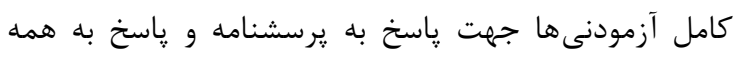

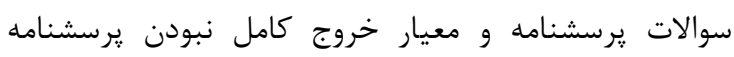

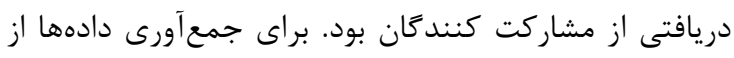
يرسشنامه هاى ذيل استفاده شد.

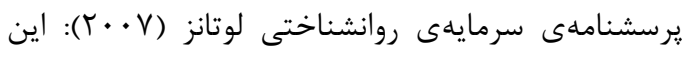

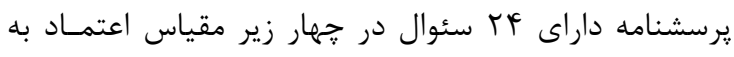

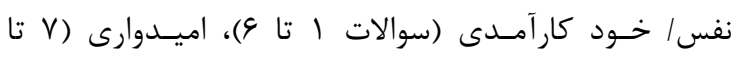

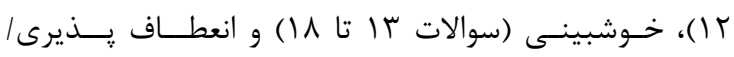

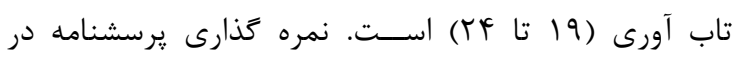

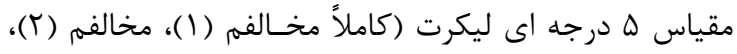

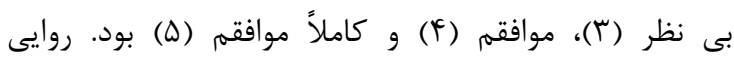
محتوايى يرسشنامه مورد تاييد متخصصان و اساتيد صاحبنظر

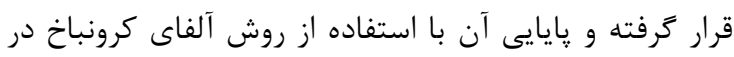

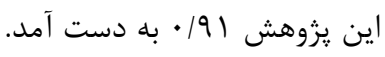

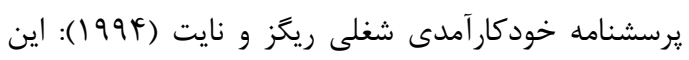

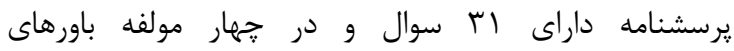
خودكار آمدى فردى (• (1-1)، انتظار بيامدهاى فردى (1) (1) -11)،

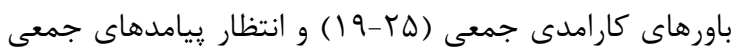

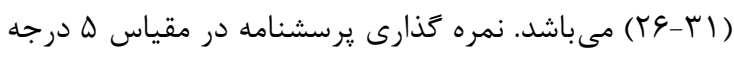

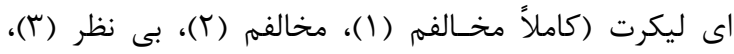

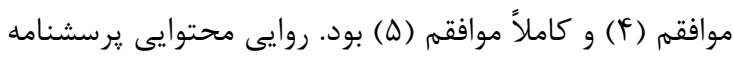

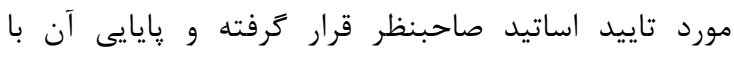

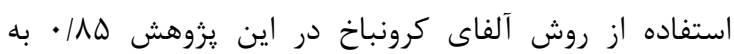

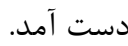
يرسشنامه سازكًارى شغلى ديويس و لافكوايست (1991) (199):

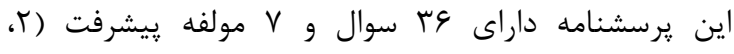
(I)

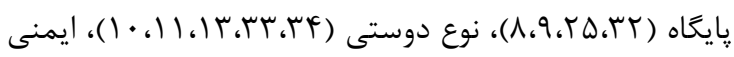

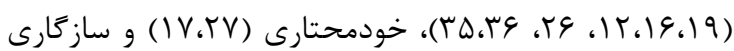

جدول ا: ميانگين، انحراف استاندارد و ضريب همبستكى بين متغيرها

\begin{tabular}{|c|c|c|c|c|c|}
\hline سر مايهى روانشناختى & خودكار آمدى شغلى & سازكارى شغلى & انحراف استاندارد & ميانكَين & متغير ها \\
\hline 1 & $\cdot / r \wedge \kappa^{* *}$ &. $\mid 4 q 1^{* *}$ & $11 / \cdot 1$ & $91 / 41$ & سرمايهى روانشناختى \\
\hline & 1 & •/rrq** & $19 / 4$. & $1 \cdot r|9|$ & خودكار آمدى شغلى \\
\hline- & - & 1 & $\mid \Delta / \Gamma \Lambda$ & $11 r / 9 \Lambda$ & سازگارى شغلى \\
\hline
\end{tabular}

$* * \mathrm{p} \leq \cdot / \cdot 1$ 
جدول r: مقدار آماره آزمون KMO و بارتلت

\begin{tabular}{|c|c|c|c|}
\hline$\cdot / \Lambda V$ & & آزمون KMO & \multirow{4}{*}{ بر سشنامه سر مايهى روانشناختى } \\
\hline TMI/IS & $\chi^{2}$ & \multirow{3}{*}{ 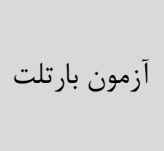 } & \\
\hline 11 & درجئ آزادى & & \\
\hline$\cdot 1 \cdots$ & $\mathrm{P}$-value & & \\
\hline$\cdot / \wedge \Delta$ & & \multirow[t]{2}{*}{ آزمون KMO } & \multirow{4}{*}{ يرسشنامه خودكار آمدى شغلى } \\
\hline rol/s. & $\chi^{2}$ & & \\
\hline rI & درجة آزادى & \multirow[t]{2}{*}{ 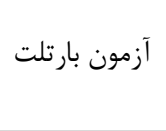 } & \\
\hline$\cdot 1 \cdots$ & P-value & & \\
\hline$\cdot / 91$ & & \multirow[t]{2}{*}{ آزمون KMO } & \multirow{4}{*}{ برسشنامه سازكًارى شغلى } \\
\hline TEI/KT & $\chi^{2}$ & & \\
\hline ra & درجئ آزادى & \multirow[t]{2}{*}{ 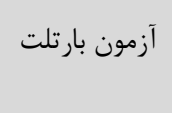 } & \\
\hline$\cdot / \cdots$ & P-value & & \\
\hline
\end{tabular}

بر اساس جدول r مى توان كَفت كه اثر مستقيم

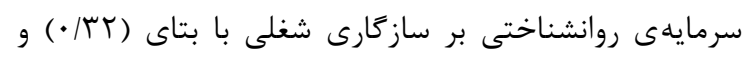

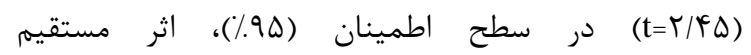

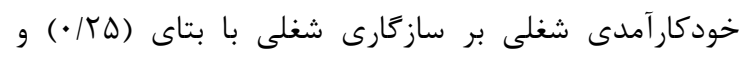

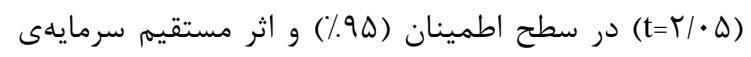

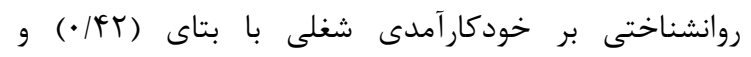

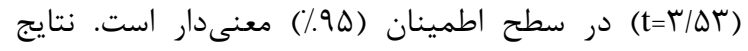

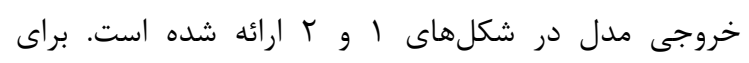

(1) داده شده است كوجكتر از مقدار ه • • بوده و فرض يكه

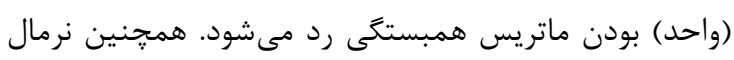

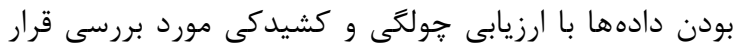

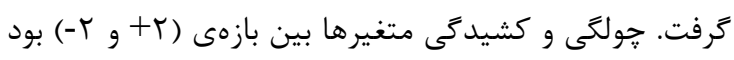

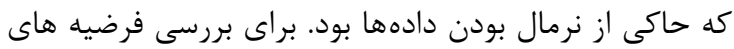

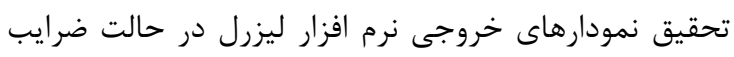

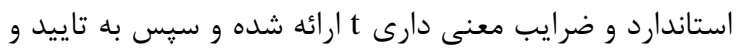
رد فرضيه هاى يزوهش خواهيم : يرداخت.

\begin{tabular}{|c|c|c|c|c|}
\hline \multirow[b]{2}{*}{$\mathbf{t}$} & \multirow[b]{2}{*}{ اثر غير مستقيم } & \multirow[b]{2}{*}{ اثر مستقيم } & \multicolumn{2}{|c|}{ مسير } \\
\hline & & & به متغير & از متغير \\
\hline$r / F \Delta$ & .11 & (rt & ساز حارى شغلى & سرمايهى روانشناختى \\
\hline$r / \cdot \Delta$ & - & $\cdot / r \Delta$ & ساز كارى شغلى & خودكار آمدى شغلى \\
\hline r/QT & - & . IFt & خود كار آمدى شغلى & سرمايهى روانشناختى \\
\hline
\end{tabular}

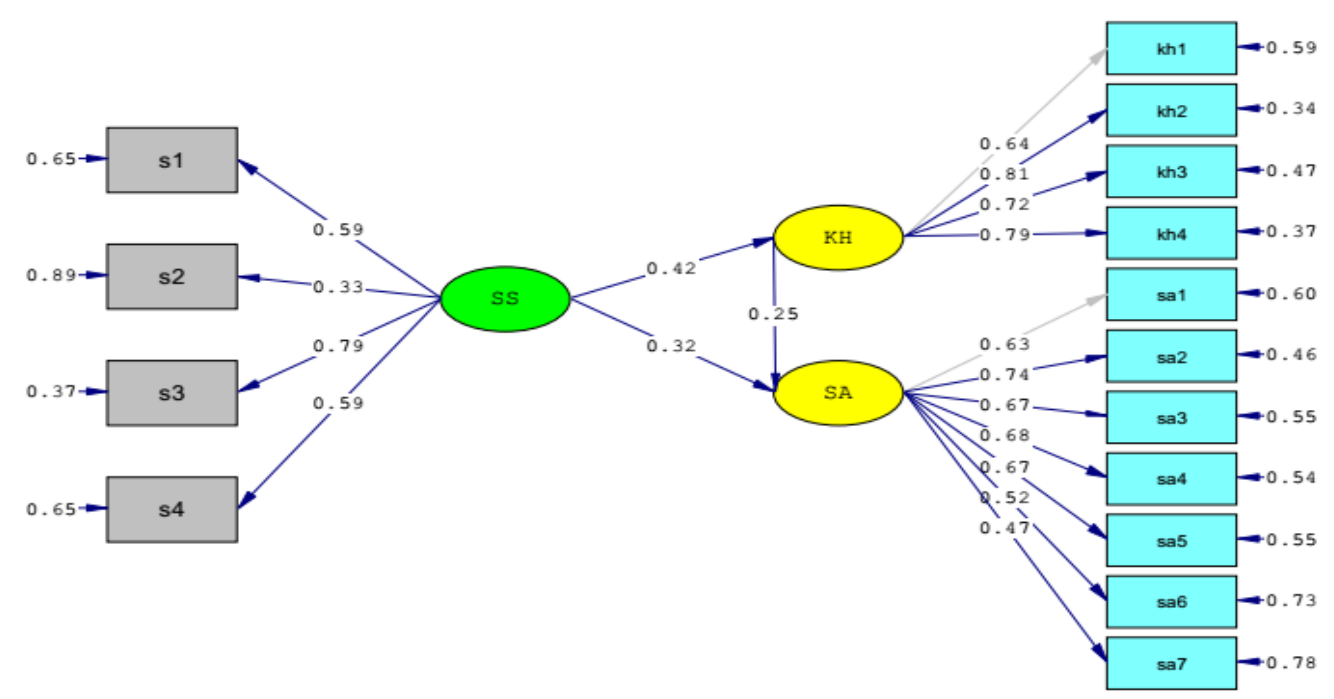

Chi-Square=139.14, df=87, P-value=0.00033, RMSEA=0.070

شكل (: ضرايب تخمين استاندارد مدل ساختارى يروهش .000 


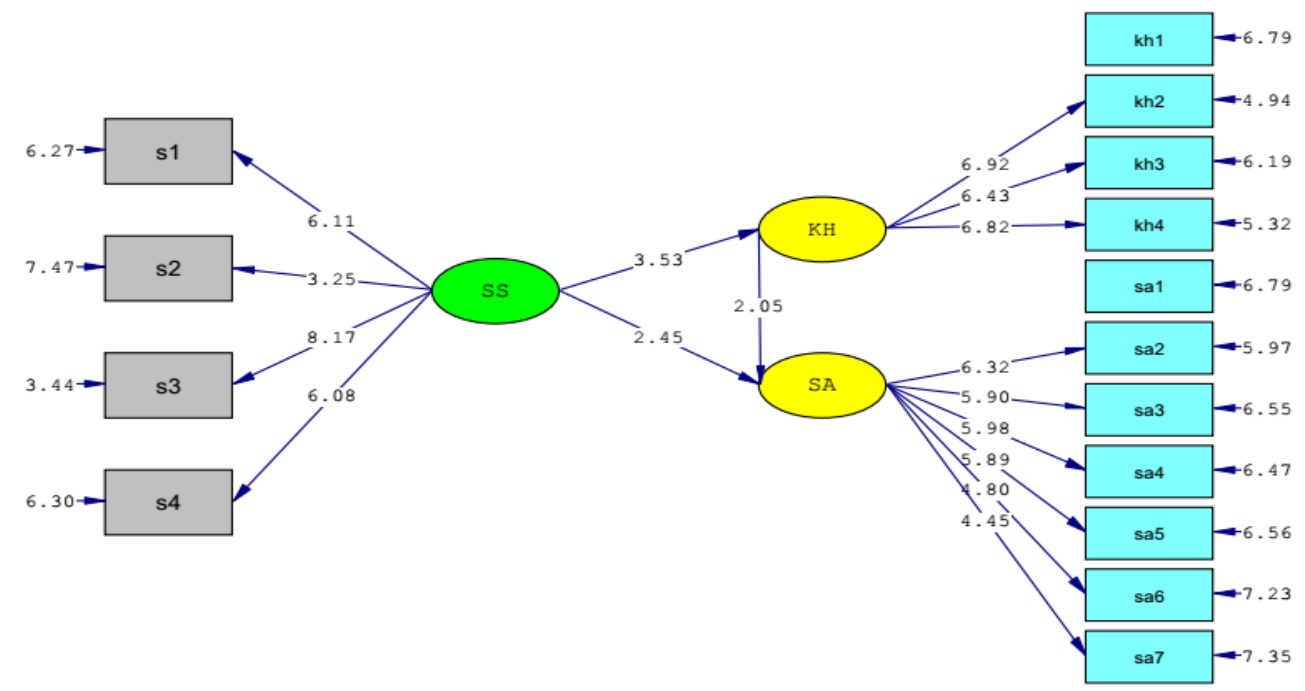

Chi-Square=139.14, df=87, P-value=0.00033, RMSEA=0.070

$$
\text { شكل r: ضرايب معنى دارى T T }
$$

نتايج جدول f ن نشان مى دهد كه ضريب شاخص ريشه

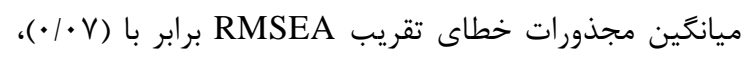

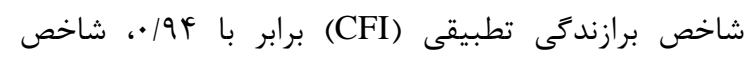

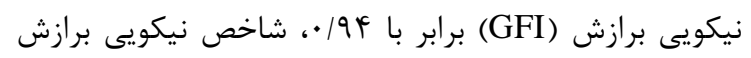

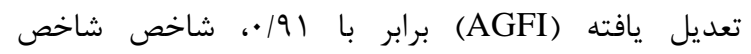

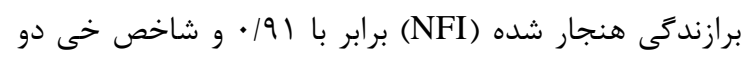

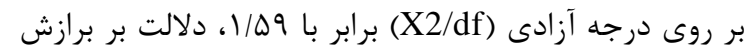
مناسب و متوسط مدل دارد.
بررسى تاثير غير مستقيم سرمايهى روانشناختى بر سازگًاى

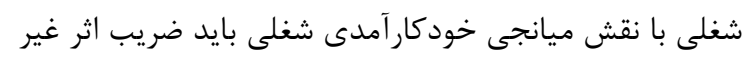

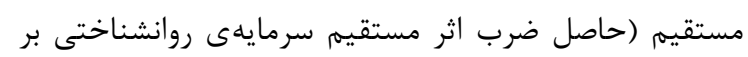

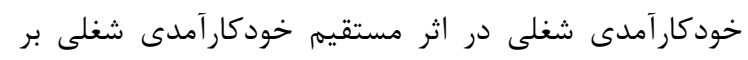

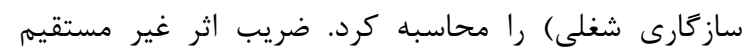

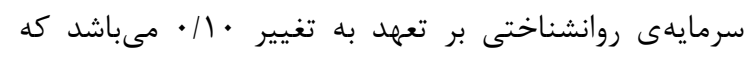

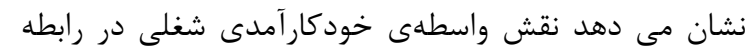

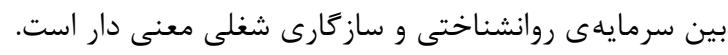

جدول fا: برازش مدل يزوهش بر اساس شاخصهاى برازندگى

\begin{tabular}{|c|c|c|c|c|}
\hline وضعيت & مقادير ايدهآل & 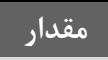 & Model fit & شاخصهاى برازش \\
\hline مطلوب & $>\cdot 10$ & Irq/IF & $\mathrm{X}^{2}$ & خى دو \\
\hline- & - & $\Lambda \vee$ & $\mathrm{df}$ & درجه آزادى \\
\hline 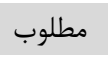 & $<r$ & $1 / 09$ & $\mathrm{X}^{2} / \mathrm{df}$ & خى دو/ درجه آزادى \\
\hline 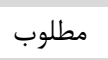 & $<\cdot 1 \cdot \wedge$ & $\cdot / \cdot V$ & RMSEA & ريشه ميانكَين توان دوم خطاى تقريب \\
\hline 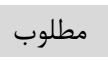 & $>\cdot 19$ & $\cdot / 94$ & GFI & نيكويى برازش \\
\hline 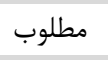 & $>\cdot / 9$ & $\cdot 191$ & AGFI & نيكويى برازش تعديل شده \\
\hline مطلوب & $>\cdot 19$. &.$/ 9 F$ & TLI & تاكر و لوييس \\
\hline 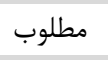 & $>\cdot / 9$ & .194 & CFI & برازش مقايسه اى \\
\hline 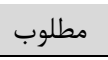 & $>\cdot 19$ &.$/ 91$ & NFI & برازش افزايشى \\
\hline
\end{tabular}

سازكارى شغلى افراد همسو است. در تبيين تأييد اين رابطه

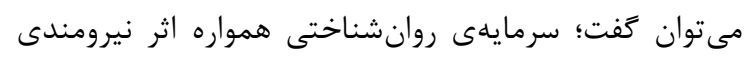

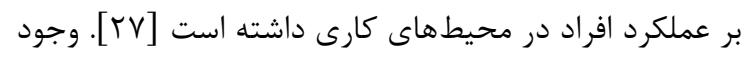

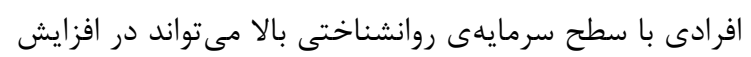

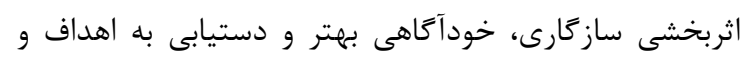

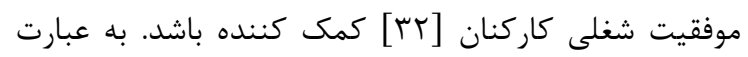
ديخر به نظر مىرسد هر كدام از قابليتهاى سركان سرمايهى روانشناختى، نقش منحصر به فردى در ييامدهاى كاركنان
هدف اين يزوهش بررسى رابطه بين سرمايهى

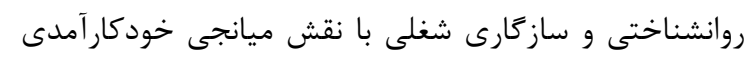

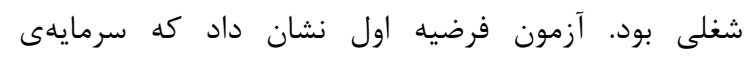

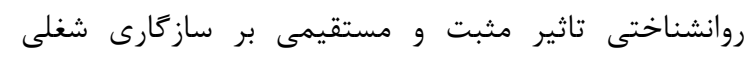

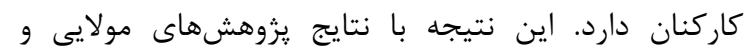

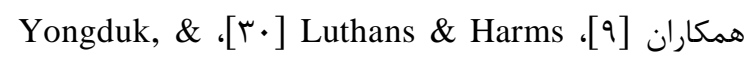
Hodges , [rø]Bitmis \& Ergeneli, ، [r৫] Dongseop [با] مبنى بر تأثير مستقيم سرمايهى روانشناختى بر 
كاركنان دارد. اين يافته با نتايج يزوهشهاى مرعشيان و

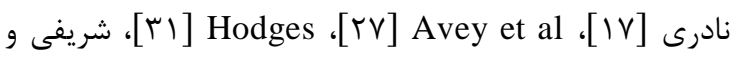

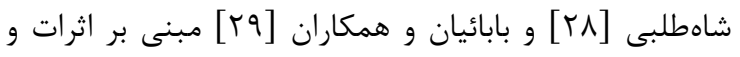
رابطه سرمايهى روانشناختى بر خودكارآمدى شغلى كاركنان آنسان

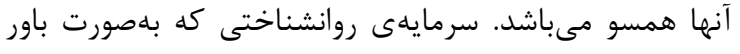

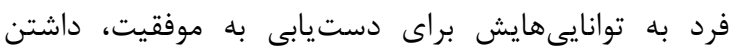

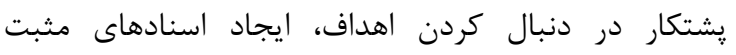
دربارهى خود و تحمل كردن مشكلات در نظر كرفته شده إنها است، همواره يكى از عوامل موثر بر خودكارامدى امدى افراد در درد

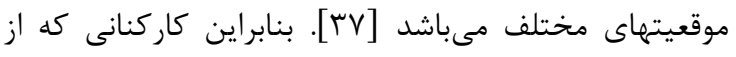

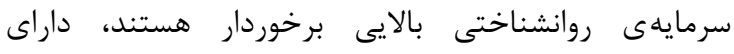

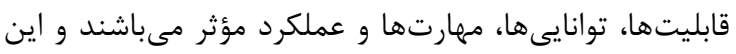

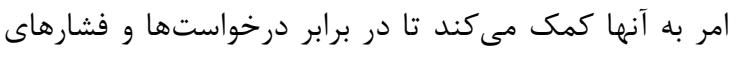

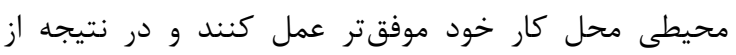

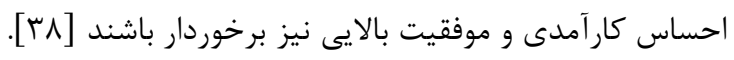

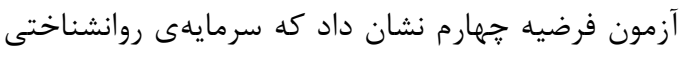
به طور غير مستقيم بر سازكارى شغلى كاركنان تاثير دارد و

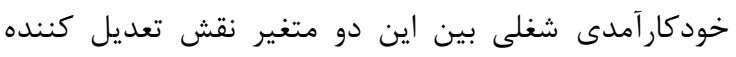

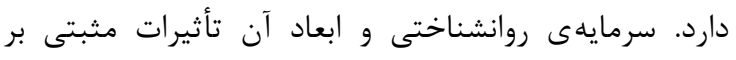

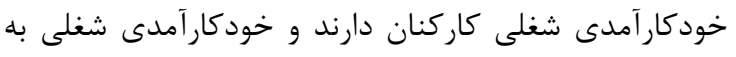

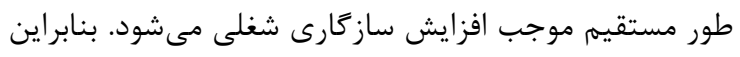

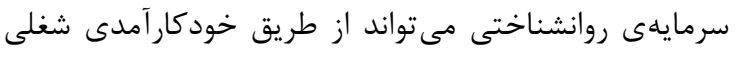

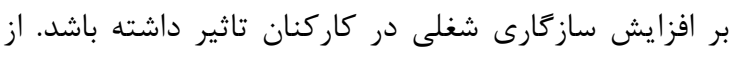

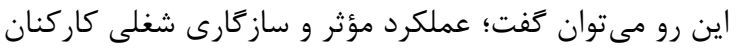

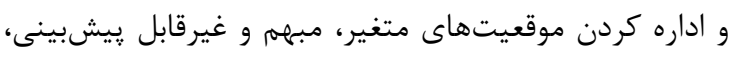

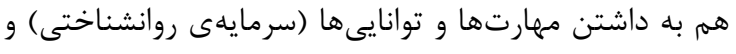

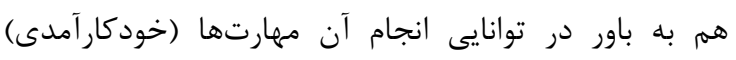

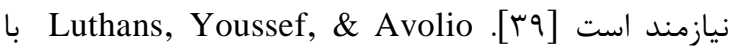
يزوهشهايى كه در اين زمينه انجام دادند، به اين نتيجه

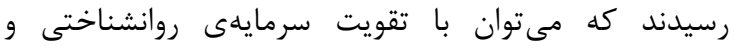

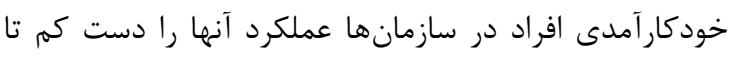

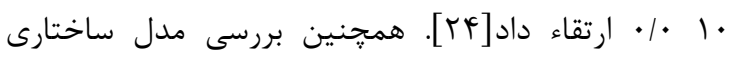

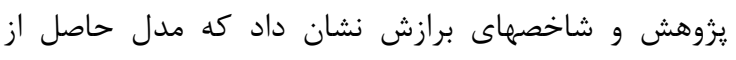

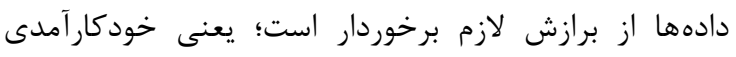

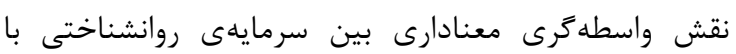
سازگارى شغلى ايفا كرده است.

\section{نتيجه تيرى}

به طور كلى نتايج اين يزوهش نشان داد كه سرمايهى

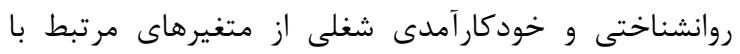

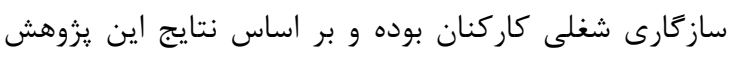

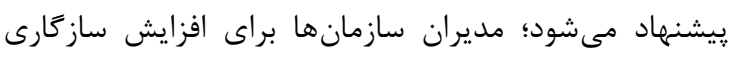

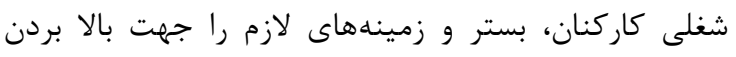

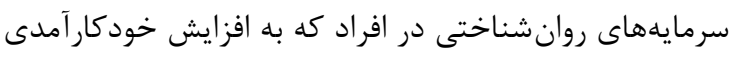

دارند. مثلاً كسانى كه در شغل خود، خودكارآمدى بالايى دارند، مقدار تلاش بيشترى در انجام وظيفه به كار مى بـرند.

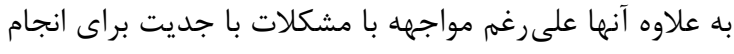

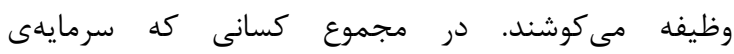
روانشناختى بالايى دارند، اميدوار هستند كه با داشتن اراده و

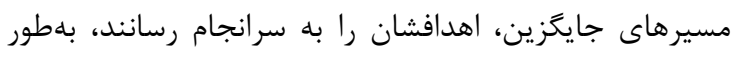

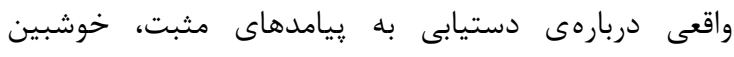

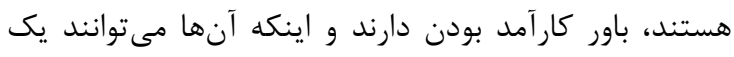

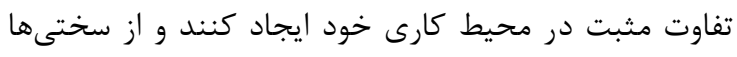

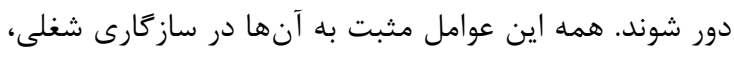

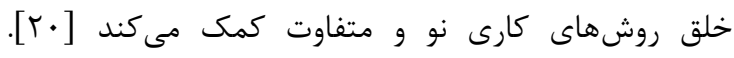

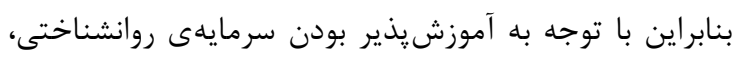

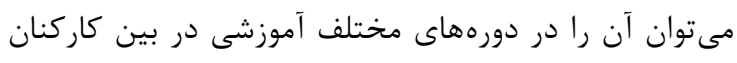

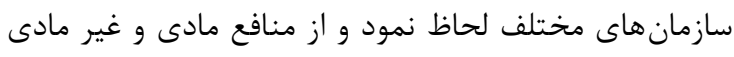

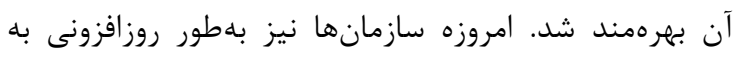

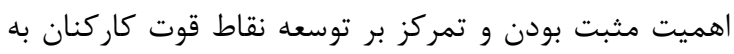

جاى نقاط ضعف آنها يى بردهاند [سب].

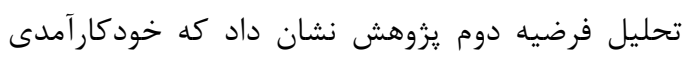

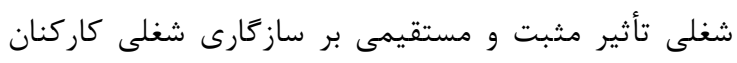

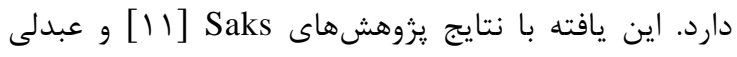

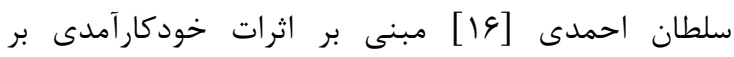

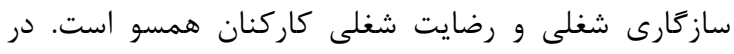

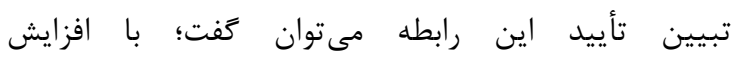
خودكارآمدى، سازحارى شغلى نيز افزايش يافته و بالعكس.

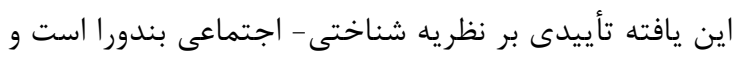

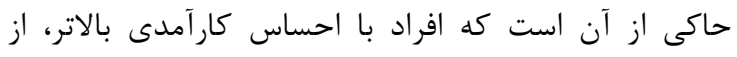

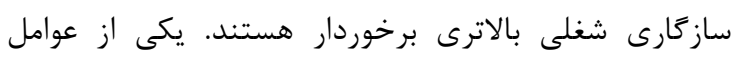

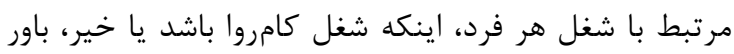

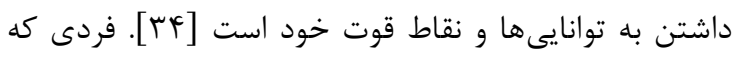

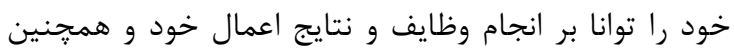

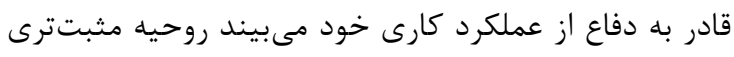

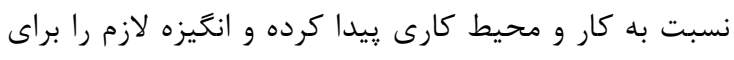

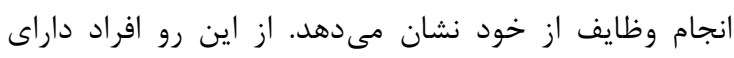

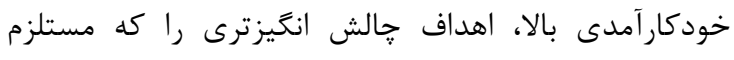
تلاش بيشترى است، انتخاب مى كنند و در نتيجه استقامت،

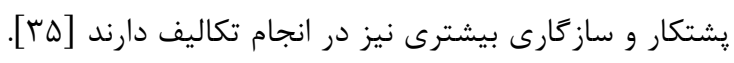

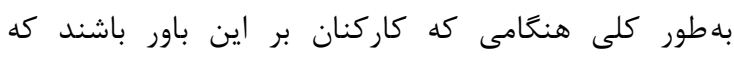

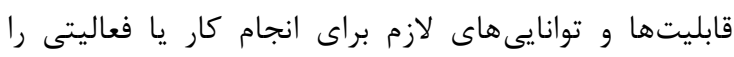

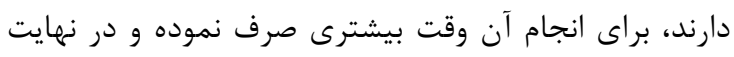

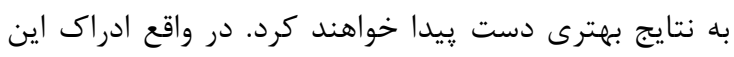

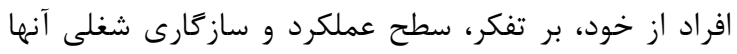

تأثير مى گذارد [عب]. آزمون فرضيه سوم يزوهش نشان داد داد كه سرمايهى

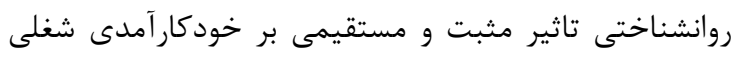


راهكارهاى كاربردى در راستاى افزايش آن، يافتههاى يُروهش حاضر را قوت خواهد بخشيد.

$$
\begin{aligned}
& \text { تشكر و قلرواذى }
\end{aligned}
$$

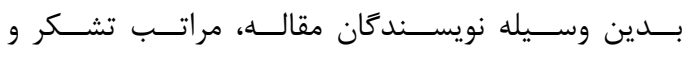

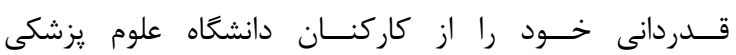

$$
\begin{aligned}
& \text { كرمانشاه كه مـا را در اجـراى اين يزوهش كمى نم نمودند، اعلام }
\end{aligned}
$$

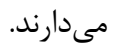

تضاد منافع

اين مطالعه براى نويسنده هيج گونه تضاد منافعى نداشته

$$
\begin{aligned}
& \text { نيز مى انجامد، فراهم نمايند. به اين منظور، بركزارى دورههاى }
\end{aligned}
$$

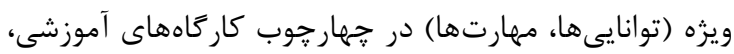

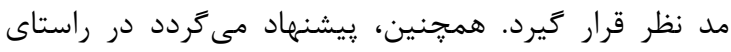

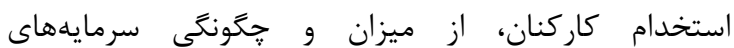

$$
\begin{aligned}
& \text { روانشناختى افراد نسبت به شغل اطلاع حاصل نموده، منان، }
\end{aligned}
$$

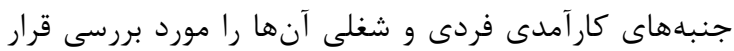

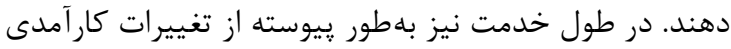

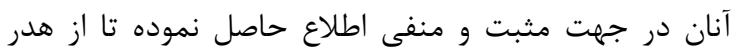

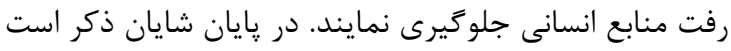

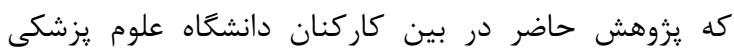

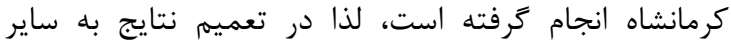

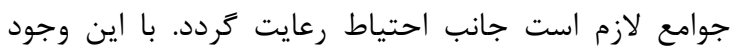

$$
\begin{aligned}
& \text { انجام يزوهشهاى بيشتر در زمينه سازگًارى شغلى و وارئ ارائه }
\end{aligned}
$$

\section{REFERENCES}

1. Leitao J, Franco M. Individual entrepreneurship capacity and performance of SMEs, Munich Personal RePEc Archive. MPRA: Papers University Library of Munich; 2008. https://mpra.ub.uni-muenchen.de/id/eprint/8179

2. Shafie Abady A. Tips and career advice and professional and career choice theories. Tehran: Roshd publication; 2006. (Persian)

3. Yarmohamadzade P, Dadashzade M. Study the role of cultural intelligence and social capital in teachers Job compatibility: Testing mediating role of social capital. Journal of modern educational approaches, 2015; 10 (1): 4166. (Persian).

4. Kapel DE, Newka E. American Educator,s Encyclopedia, New york.Greeweed Press; 1997.

5. Dawis RV, Lofquist LH. A psychological theory of work adjustment: An individual differences model and its applications. Stoughton, Massachusetts: Books on Demand; 1997.

6. Kuang C.H, \& Ying Ch. C. The work adjustment of taiwanese expatriates. The business review; 2007. 8, 267.

7. Dawis R.V. \& Lofqist L.H. A psychological theory of work adjustment, Minneapolis: University of Minnesota press; 1998.

8. Kristension P, Nordhagen R, Wergeland E, \& Bjerkedal T. Job adjustment and absencen from work in midpregnancy in the Norwegian mother and child cohort study(MoBa), JBMJ Publishing Group; 2007.

9. Molaei a, Yazdanbakhsh K, Karamy J. Relationship between Personality Characteristics (five factor model) and Locus of Control with Vocational Adjustment of Gas Company Employees in Kermanshah. Journal of personality \& Individual Differences. 2014; 3 (4): 107-121. [Persian]. http://www.sid.ir/FileServer/JF/10002513930407

10. Heidari H, Khashei V. Analysis of the relationship between job characteristics and job adjustment of alumni. Quarterly Journal of Research and Planning in Higher Education. 2016; (1) :127-143. [Persian].

11. Saks A.M. Longitudinal field investigation of the moderating and mediating effects of self-efficacy on the relationship between training and newcomer adjustment. Journal of Applied Psychology,2005; 80(2), 211-225. PMID:7737934

12. Rajaby GH, Atary Y, Shokrkon H. Validate and compare the expectations of self-employment in male and female students shahid Chamran University. Journal of Education and Psychology, University of shahid Chamran,2003; 11(1,2). 71-100. [Persian]. http://www.ensani.ir/fa/content/ 83801/default.aspx

13. Riyo J. motivation and excitement. Translated by Yahya Saeid mohamady.Virayesh publication; 2007.

14. Bandura A. A socio-cognitive view on shaping the future. Seoul, Korea: HK Mun Publishing; 1996.
15. Schaufeli W.B, \& Marisa S. Efficacy or inefficacy, that's the question: Burnout and work engagement, and their relationships with efficacy beliefs, Anxiety, Stress, and Coping. 2007; 20(2), 177_196. 10.1080/ 10615800701217878

16. Abdeli Soltan-Ahmadi J, Eisazadegan A, Gholami M.T, Mahmodi H \& Amani J. The relationship between collective efficacy beliefs and self-efficacy with job satisfaction of secondary school male teachers in Qom. 2012; 4 (10): 105124. [Persian]. http://www.sid.ir/fa/journal/ViewPaper. aspx?id=177301

17. Marashian F, \& Naderi F. Relations of Organizational Culture, Emotional Intelligence and Psychological Capital with Job Self -efficacy and Organizational Entrepreneurship among the Employees of Khuzestan Water and Power Organization. Knowledge \& Research in Applied Psychology. 2013; 14 (3): 112- 121. [Persian]. http://www.sid.ir/fa/journal/ViewPaper.aspx?id=221034

18. Luthans F. Organization Behavior, 11th ed ,MC Graw- Hill; 2008

19. Peterson C. The future of optimism. Am . 2000; 55(1):4455. http://dx.doi.org/10.1037/0003-066X.55.1.44

20. Snyder C. R. Hope and Optimism. Encyclopedia of Human Behavior. 1994:2,. 535- 542). San Diego: Academic Press. Snyder, C.D. Hope Theory: Rainbows in the Mind, Psychological Inquiry, 2002.13(4), 249-275.

21. Luthans F, Avey J, Avolio B, \& Patera J. Experimental Analysis of a Web-based Intervention to Develop Positive Psychological Capital. Academy of Management Learning and Education. 2008; 7(2); 209-221. 10.5465/AMLE. 2008.32712618

22. Erez A, Judge T. Relationship of core selfevaluations to Goal Setting, Motivation, and Performance. J Appl Psychol. 2001; 86(6):1270-1279. 11768067

23. Judge T, Bono J. Relationship of core selfevaluations traits - self-esteem, generalized selfefficacy, locus of control, and emotional stability With job satisfaction and job performance: A meta-analysis. J Appl Psychol. 2001; 86:8092. PMID:11302235

24. Luthans, F., Youssef, C.M., Avolio, B.J. Psychological capital: developing the human competitive edge. Published by Oxford, University Press,Version:1.2001.

25. Yongduk Ch. \& Dongseop L. Psychological capital, Big Five traits, and employee outcomes. Journal of Managerial Psychology. 2014; 29, No. 2. http://www. emeraldinsight. com.

26. Bitmis M. G, \& Ergeneli A. How Psychological Capital Influences Burnout The Mediating Role of Job Insecurity. Social and Behavioral Scoences,2016; 207, 363- 368. 10.1016/j.sbspro.2015.10.106

27. Avey J.B, Luthans F, Youssef C.M. The Additive Value of Positive Psychological Capital in Predicting Work Attitudes 
and Behaviors Journal of Management. 2009; 36(2), 430452. http://digitalcommons.unl.edu/leadershipfacpub/6

28. Sharifi N S, Shahtalebi B. Investigation of the Relationship between Dimension of Psychological Capital with Organizational Commitment and Job Performance. Social Welfare. 2015; 15 (59) :148-119. [Persian]. URL: http://refahj.uswr.ac.ir/article-1-2380-fa.html

29. Babayian A, Saeid naghaviy M, Alizade H, Poorgholamy M. The effect of psychological capital on job satisfaction of male officers police. Journal of security management. 2011; 7(3): 346-369. [Persian]. https://elmnet.ir/Article/113301025857/

30. Harms P.D, Luthans F. Measuring implicit psychological constructs in organizational behavior: An example using psychological capital, Journal of Organizational Behavior. 2002; 3(4), 589-594. 10.1002/job. 1785

31. Hodges T. D. An experimental study of the impact of psychological capitalon performance, and the contagion effect. Doctoral dissertation. [Ph.D. Thesis]. University of Nebraska-Lincoln; 2011.

32. Saeid abaszade, M., yasraby, A. The relationship between employee engagement and organizational climate of schools and teachers in Saqez. Journal of Urmia University Faculty of Literature and Human Sciences, (Psychology and Educational Sciences). 2007; 1(5). 47-76. [Persian]
33. Luthans F, Luthans KW, Luthans BC. Positive psychological capital: Beyond human and social capital. Business Horizons. 2004; 47(1): 45-50. 10.1016/j.bushor. 2003.11.007

34. Bandura A. Cultivate self-efficacy for personal and organization In E.A. Locke (Ed.), The Blackwell Handbook of Principles in Organization Behavior. London: Blackwell Publishing: 2007.

35. Tahmaseby M, Salehy M, Gholtash A. The Relationship between Employees' Self-Efficiency and Organizational Support with their Organizational Citizenship Behavior. New Approaches in Educational Administration. 2015; 6(4). 81-91. http://jedu.miau.ac.ir/article_1864_133.html

36. Parvin E. personality psychology. Translated by Javady, M., Kadivar, P.,. Ressa publication; 1998. [Persian]

37. Gohel K. Psychological capital as a determinant of employee satisfaction. Shodh, Samiksha Aur Mulyankan, 2002; 3(36): 34-37.

38. Aghdamy Bahher A, Najjarpoor S, Livajany $+\mathrm{SH}$. The relationship between emotional intelligence and sense of self-efficacy and burnout among staff at the University of Tabriz. Training and Assessment. 2009; 2(7). 99-119. [Persian]

39. Bandura A. Self- efficacy: The exercise of control. New York: Freeman;1997. 